\title{
Pathogenesis of Vocal Fold Nodules: New Insights from a Modelling Approach
}

\author{
Philippe H. Dejonckere ${ }^{a, b}$ Malte Kob ${ }^{c, d}$ \\ ${ }^{a}$ Institute of Phoniatrics, University Medical Centre, Utrecht, The Netherlands; ${ }^{b}$ Federal Institute of \\ Occupational Diseases, Brussels, Belgium; ' $\mathrm{RWTH}$ Aachen University, Aachen, and ${ }^{\mathrm{d}}$ Detmold University of Music, \\ Detmold, Germany
}

\section{Key Words}

Vocal fold nodules · Muscular tension imbalance .

Vibrating vocal folds, 3-dimensional computer model

\begin{abstract}
Objective: To give new insights into the pathogenesis of vocal fold nodules: (a) why the female/male ratio is so extreme, (b) how an hourglass-shaped vibration pattern - eliciting a localized microtrauma - originates, and (c) what the roles of muscular tension imbalance and of behavioral aspects are. Materials and Methods: Simulations with a 3-dimensional computer model of the vibrating vocal folds. Results and Conclusion: (1) A slightly incomplete dorsal vocal fold adduction is a first condition for inducing an hourglass vibration pattern. (2) A limited collision zone is only possible with a small degree of curving of the rest position of the vocal fold edges in their ventral portion. This is an anatomical characteristic of the adult female larynx. Muscular fatigue and resulting hypotonia seem to enhance this curving. (3) If both these conditions are fulfilled, a sufficient vibration amplitude is required to achieve a localized impact. (4) This third condition can be obtained by an increased subglottal pressure and/or by a decrease in active stress of the tension forces between the neighboring vocalis masses. These last aspects incorporate muscular tension imbalance (dyskinesia) and behavioral aspects in the modelling process. Decrease in active stress is a possible effect of fatigue, and increase in subglottal pressure a result of effort compensation.
\end{abstract}

Copyright $\odot 2009$ S. Karger AG, Basel
(C) 2009 S. Karger AG, Basel

1021-7762/09/0613-0171\$26.00/0

Fax +4161306 1234

E-Mail karger@karger.ch

www.karger.com
Accessible online at: www.karger.com/fpl

\section{Introduction}

Vocal fold nodules are one of the most common laryngeal (histo)pathological changes [1]. They appear as small, bilateral, mostly quite symmetric mass lesions (thickenings) approximately at the junction of the ventral and middle third of the fold and result in an hourglass closure glottal configuration [2]. Since the first description by Türck (1866) [3], discussions on and controversies about etiology have not ceased [2]. An example of an intriguing aspect is the male/female ratio of vocal fold nodules in adults, which appears excessively imbalanced $[1,4,5]$ : about $95 \%$ females versus 5\% males. The difference in mean speaking frequency $(110-131 \mathrm{~Hz}$ in males and 196$233 \mathrm{~Hz}$ in females) [6] provides only a partial explanation.

Vocal fold nodules are generally considered to be the result of vocal trauma $[4,7]$ and, more specifically, a tissue reaction to repeated localized mechanical stress or insult to vocal tissues $[8,9]$. The typical stroboscopic vibration pattern is hourglass shaped, with insufficient dorsal as well as ventral glottal closure and localized contact of vocal fold margins [5]. Such a characteristic hourglass pattern can frequently be recognized stroboscopically in early stages of development (fig. 1). The insufficient ventral closure (ventral with respect to the point of development of the nodules) is an important condition for eliciting the localized mechanical stress, which may consist of alternating (a) collision traumata $[8,10]$ and (b) tearing/shearing forces on the mucosa $[5,11]$. The latter 
Fig. 1. Vocal fold nodules in an early stage of development. a During inspiration. b During phonation, with the typical hourglass-shaped vibration pattern.
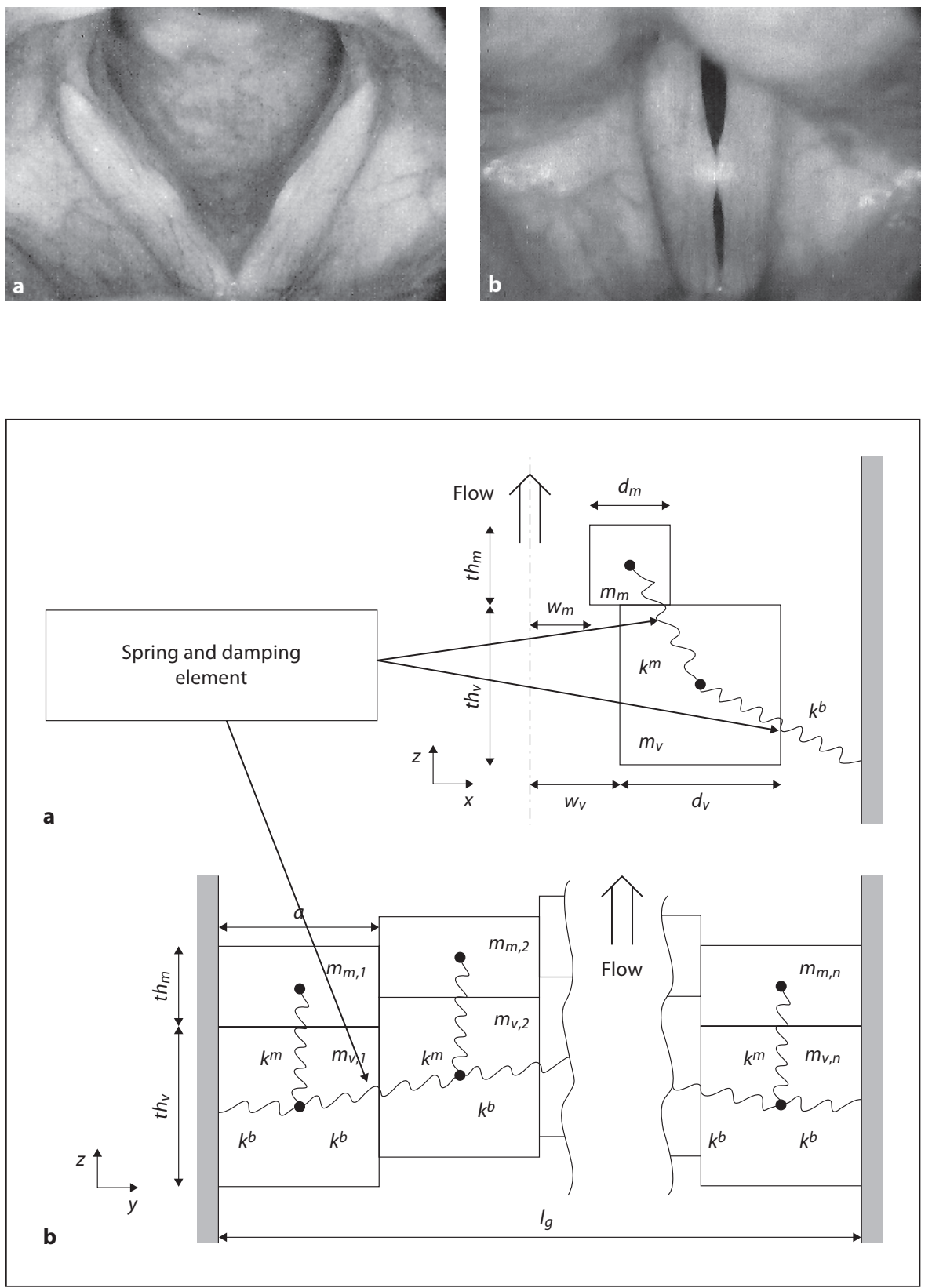

Fig. 2. Schematic sectional view (a) and lateral view (b) of the vocal fold model [13]. in the dorsal part and a slightly bowed shape of the vocal fold edge, especially in the ventral part, leads - with an oscillation of sufficient amplitude - to a limited contact zone of both folds during vibration, with alternation of localized percussion and tearing/shearing forces $[5,12]$.

A much more complex, 3-dimensional model of vibrating vocal folds was developed by Kob [13, 14], based on the 16-mass model of Titze and Strong [15] (fig. 2, 3). The arrangement of laterally discretized masses $m_{v, i}$, here with $i=20$, represents the $i$ th body segment of the vocal 
Fig. 3. Different views of the model. a 3-dimensional view. b Lateral view. c View from above ('laryngoscopic view'); ventral commissure at the bottom.

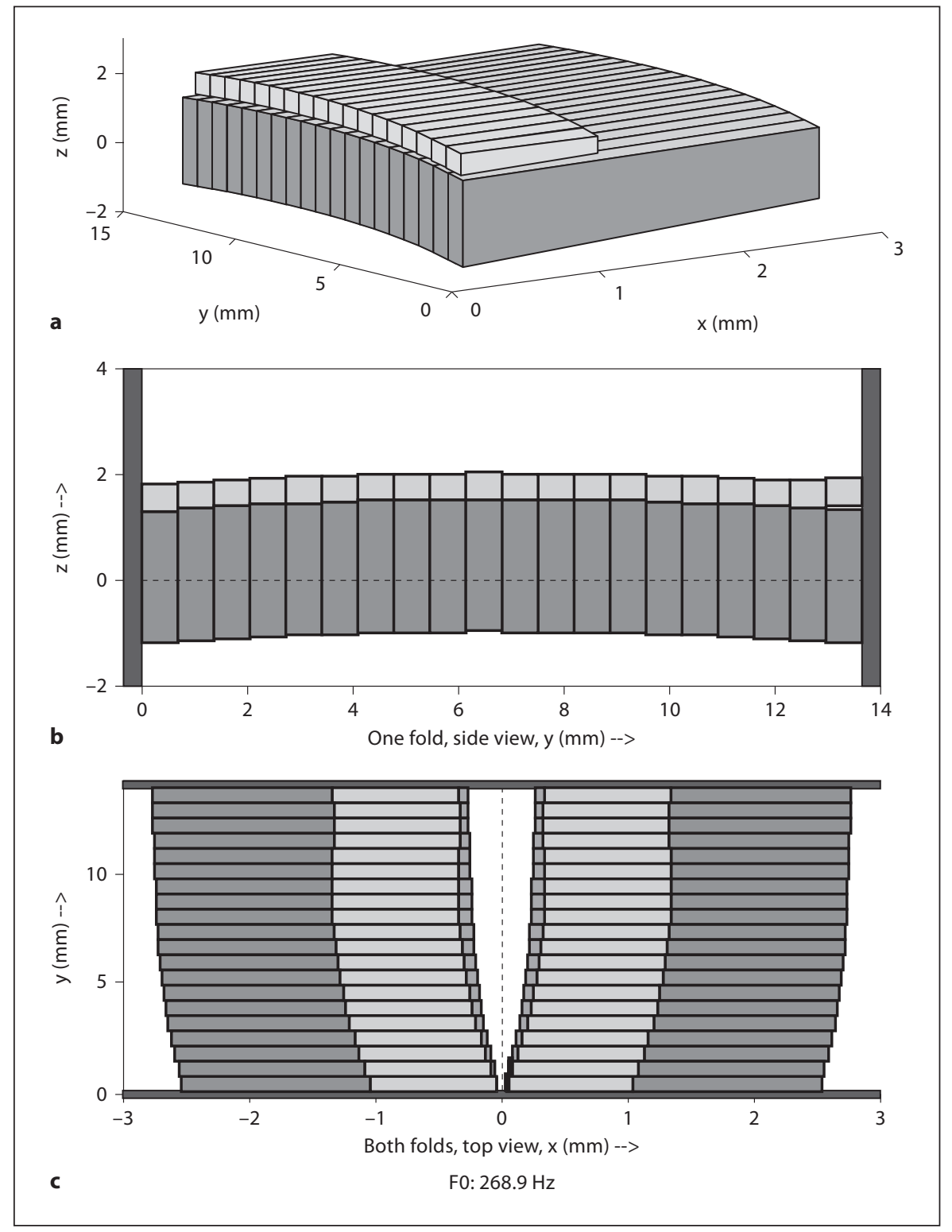

fold (mainly the vocalis muscle and the vocal ligament); $m_{m, i}$ represents the $i$ th cover segment (mainly the epithelium and superficial layer of the lamina propria). Each of the large masses $m_{v, i}$ is connected to the boundary and to neighbored masses $m_{v, i-1}$ and $m_{v, i+1}$ by a spring with stiffness $k^{b}$ and damping $D^{b}$, and to a small mass $m_{m, i}$ by a spring with stiffness $k^{m}$ and damping $D^{m}$. The sum of the lateral segments of width $a$ is the longitudinal length $l_{g}$ of the vibrating vocal fold. The active stress within the vocalis muscle results from the tension forces between the neighboring vocalis masses.
Such a dynamic physiological model, accounting for the common laryngoscopic observations, offers the possibility of independently varying each parameter. The most relevant parameters for this study are: (1) the configuration or shape of the vocal fold edge; (2) the degree of dorsal gap; (3) the subglottal pressure; (4) the active stress within the row of body masses, and (5) the stiffness of the connection between the large and small masses $\left(k^{m}\right)$.

Once all parameters are defined, the model demonstrates a 3-dimensional motion that can be frozen at critical moments for performing measurements. 
Fig.4. Different vocal fold edge shapes that were modelled and tested. From left to right: linear (L), male (M), female (F1-F4) with a slightly increasing degree of curving of the ventral part of the vocal fold edge.

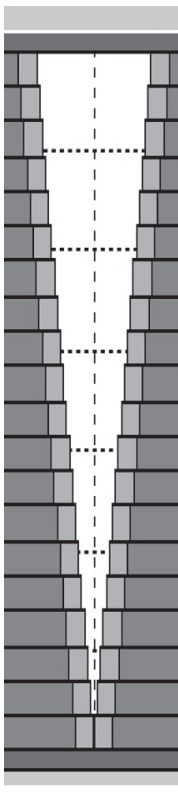

$\mathrm{L}$

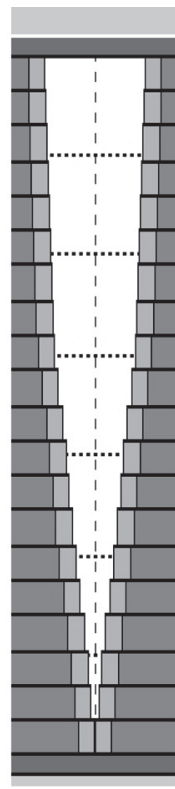

M

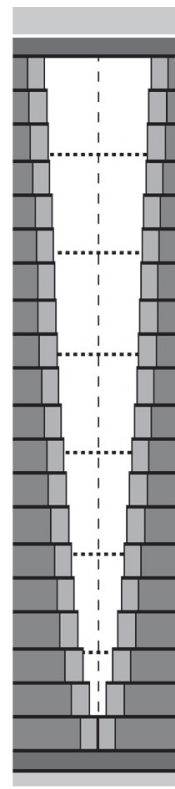

F1

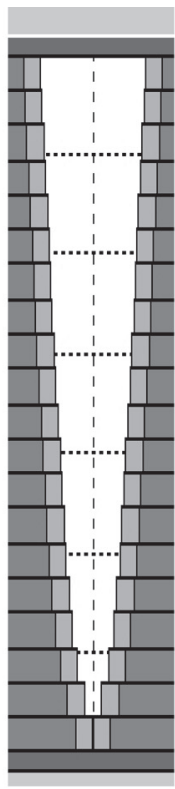

F2

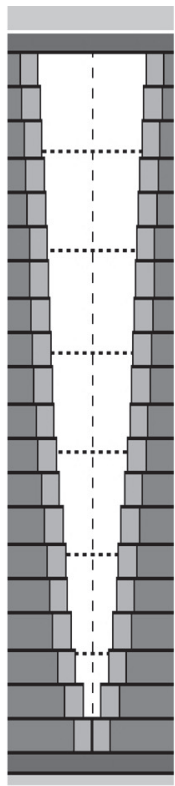

F3

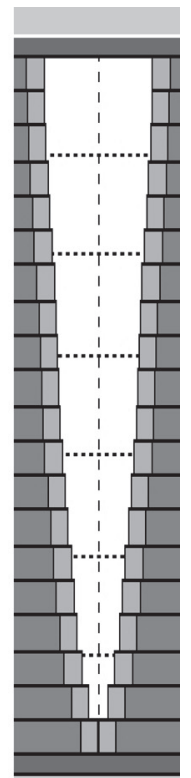

F4
The main aim of this study is, by using this new model, to investigate which conditions are to be fulfilled in order to obtain the vibration pattern with a localized vocal fold contact, at the place where vocal fold nodules are observed, and why females are more prone to achieve this hourglass-shaped oscillation pattern.

\section{Materials and Methods}

Six different shapes were considered for simulation (fig. 4), i.e. a theoretical linear vocal fold edge (L) as well as 5 different shapes derived from videolaryngoscopic recordings: 1 normal young male adult vocal fold edge in respiratory position $(\mathrm{M})$ and 4 vocal fold edges from young adult females in respiratory position (F1F4), with a slightly increasing degree of curving of the ventral part. F1 and F2 are normal subjects, while F3 is a young female student with minimal vocal fold nodules. In this last case, the small nodular swelling was eliminated by extrapolation. F4 had a vocal fold paresis.

A total of 780 animated simulations were achieved, mostly with freezing at either maximal opening or maximal closing of the glottis. During animated simulations, the transversal movement (closing/opening of glottis) can be amplified in order to allow a detailed analysis of the contact phase. At maximal closure, overlap of some right and left mass blocks may occur. The degree of overlap can be considered as reflecting the amount of kinetic energy dissipated at that location.

Standard conditions were as follows: dorsal gap, $1,200 \mu \mathrm{m}$; subglottal pressure, $980 \mathrm{~Pa}$; active stress, $60 \mathrm{kPa}$; spring stiffness $k^{m}, 1.81 \mathrm{~N} / \mathrm{m}$; spring stiffness $k^{h}, 2.515 \mathrm{~N} / \mathrm{m}$.
Statistical analyses were performed using SPSS 14 and Statistica. When multiple tests were performed on the same data set, a Bonferroni correction was systematically applied.

\section{Results}

\section{Effect of Vocal Fold Shape}

The $\mathrm{L}$ and $\mathrm{M}$ shapes give practically similar results. The 'zip closure' without any specific collision point is the rule as soon as the dorsal adduction is not complete. No kind of simulation (by varying any other parameter) can elicit an hourglass shape. On the other hand, with all female patterns (F1-F4), the combination with incomplete dorsal adduction easily provides a limited contact between edges, slightly ventral with respect to the midpoint.

For the M shape with incomplete dorsal adduction, there are significant positive correlations $(\rho>0.90$; $p<$ 0.01 ) between the subglottal pressure and the length of contact zone ('zip closure') as well as the degree of overlap, at the moment of maximal closure (fig. 5).

For L-F4 (increasing degree of curving), there is a slight decrease in distance between the location of maximal opening amplitude and the ventral commissure when the curving becomes more pronounced $(\rho=-0.71$; $\mathrm{p}<0.01)$. 
Fig. 5. Phases of a vibration cycle, as simulated by the model. Female larynx (pattern F1). Enlargement in the transversal dimension. The limited contact zone occurs at the 9th mass from the ventral commissure, and at the cranial part of the vocal fold ('cover' mass).
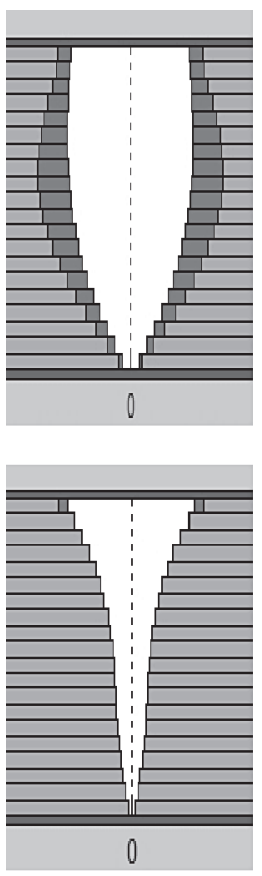
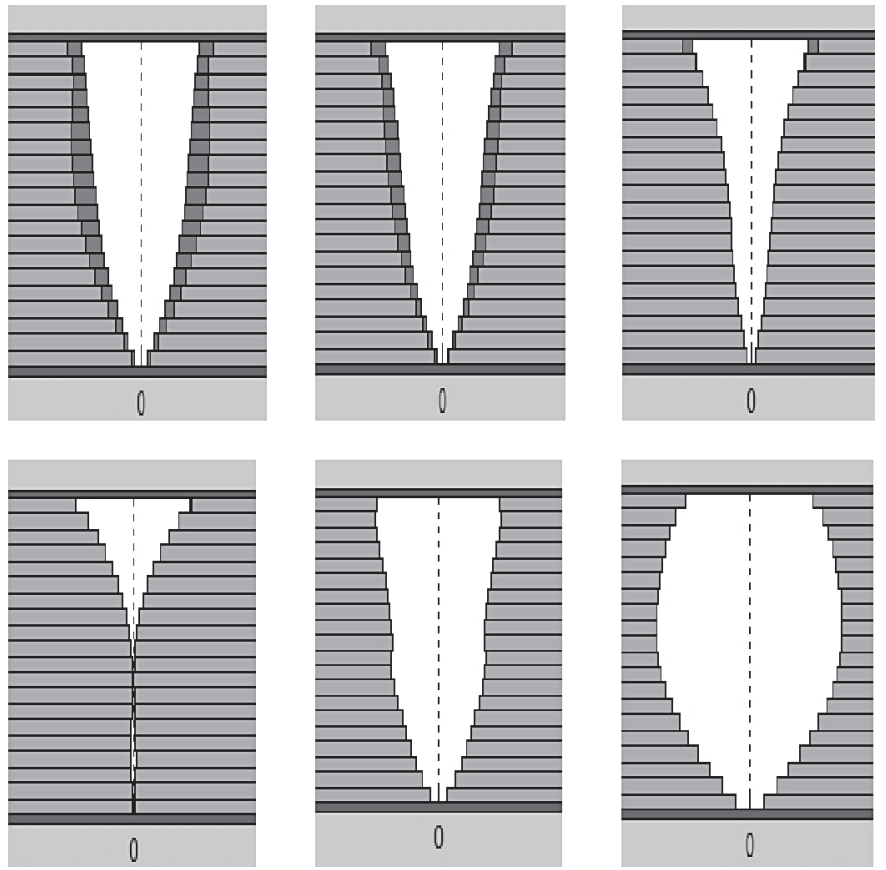

Effect of Incomplete Dorsal Adduction (F Shapes)

Positive correlations are observed between the degree of dorsal gap and (1) the distance from the center of the limited contact zone to the anterior commissure $(\rho=$ $0.55 ; \mathrm{p}<0.01) ;(2)$ the length of the ventral chink $(\rho=0.62$; $\mathrm{p}<0.01)$; (3) the length of the dorsal chink ( $\rho=0.51 ; \mathrm{p}<$ $0.01)$, and (4) the amplitude of the ventral chink $(\rho=0.48$; $\mathrm{p}<0.01)$.

Negative correlations are observed between the degree of dorsal gap and (1) the length of the contact zone ( $\rho=$ $-0.53 ; p<0.01$ ), and (2) the importance of overlap ( $\rho=$ $-0.44 ; \mathrm{p}<0.01)$.

\section{Effect of Subglottal Pressure (F Shapes)}

Positive correlations are observed between the subglottal pressure and (1) the length of the contact zone $(\rho=0.54 ; p<0.01) ;(2)$ the importance of overlap $(\rho=0.73$; $\mathrm{p}<0.01)$; (3) the maximal opening amplitude $(\rho=0.69$; $\mathrm{p}<0.01)$, and $(4)$ the vertical component of the vibratory movement $(\rho=0.59 ; \mathrm{p}<0.01)$.

A negative correlation is observed between the subglottal pressure and the length of the dorsal chink ( $\rho=$ $-0.60 ; \mathrm{p}<0.01)$.

\section{Effect of Active Stress within the Row of Body Masses}

A negative correlation is observed between the stress and (1) the maximal opening amplitude $(\rho=-0.63$; $p<$
$0.01)$; (2) the length of the contact zone $(\rho=-0.51 ; \mathrm{p}<$ $0.01)$; (3) the importance of overlap $(\rho=-0.53 ; p<0.01)$, and (4) the vertical component of the vibratory movement $(\rho=-0.60 ; p<0.01)$.

\section{Effect of the Stiffness of the Connection between the} Large and Small Masses $\left(\mathrm{k}^{\mathrm{m}}\right)$

A negative correlation is observed between this stiffness and the amplitude of mucosal wave [maximal horizontal distance between the row of large (caudal) and small (cranial) masses $(\rho=-0.42 ; \mathrm{p}<0.01)$.

\section{Discussion}

\section{Insufficient Vocal Fold Closure during Phonation Physiological Situation}

In general, glottal closure during phonation is more complete in men than in women [16]. Using videostroboscopic laryngoscopy, Södersten [17] found incomplete glottal closure in $94 \%$ of phonations in the group of normal young women and in $76 \%$ in the group of middleaged women. The most common closure pattern for both age groups was a posterior glottal chink occurring in $82 \%$ of the phonations among the young and in $61 \%$ among the middle-aged women. In soft phonation, the posterior glottal chink extended into the membranous portion of 
the vocal folds in most female subjects. The degree of closure increased significantly with increased loudness. Complete glottal closure was the most common pattern among the males, observed in $63 \%$ of phonations. These particularities, especially the location of a glottal chink, which is mostly posterior in women, were also reported by Biever and Bless [18] and Sulter et al. [19].

\section{Pathological Situations}

Two different types of dysfunction could account for the insufficient dorsal closure of the glottis during phonation: (1) hypotonia in the adductor muscles, e.g. in vocal fatigue due to overuse, as frequently occurs in professionals; (2) imbalance between tonus of adductor and abductor muscles, i.e. insufficient relaxation of posterior cricoarytenoid muscles, e.g. in muscular tension dysphonia due to stress, which is also common in voice professionals [20].

\section{The Curved Configuration of the Vocal Fold Edge:}

Achieving a Ventral Chink

Anatomical Situation

Measurements on histological specimens (section at glottal level) of normal human larynges (obtained from autopsy of subjects aged 18-45 years) demonstrated that, at its most ventral part, the membranous glottis is wider in females than in males [12]. This particularly concerns the first millimeters' distance from the commissure. The average length of the ventral macula flava is about 1.5 $\mathrm{mm}$ [21]. Hirano et al. [22] also reported that, in excised human larynges, the anterior commissure angle, i.e. the angle formed by the two straight lines from the ventral commissure to each processus vocalis, was larger in females than in males. The mean values were $16^{\circ}$ (SD 5) for males $(n=10)$ and $25^{\circ}($ SD 6$)$ for females $(n=10)$. Furthermore, the angle of the laminae of the thyroid cartilage is also larger in females $\left(120^{\circ}\right)$ than in males (average $90^{\circ}$ ) [23]. All these findings support the assumption that insufficient ventral closure seems to be achieved more easily in females than in males, and this is clearly confirmed by our simulations.

\section{Physiological Situation}

Contrary to the laryngoscopic aspect in a normal subject, the margin of the vocal fold appears distinctly bowed in histological specimens of horizontal sections at the glottal level, as it is in case of denervation, even before muscular atrophy has occurred. This seems mainly due to the loss of muscular tonus in the musculus vocalis: the shape of the vocal fold margin then becomes mainly de- termined by fibroelastic structures of the ligamentum vocale (which can be considered as a local thickening of the conus elasticus) and the maculae flavae. To a lesser extent, a functional paresis related to vocal fatigue or hypotonia could determine a similar effect: Stemple et al. [24] observed that fatigue (achieved by experimental vocal loading in normal adult females) of the thyroarytenoid muscle leads to bowing of the vocal fold. They also found that an anterior glottal chink is a diagnostic sign of laryngeal fatigue. This of course may result in breathiness.

\section{The Collision and Tearing/Shearing Forces in the Localized Impact Zone}

Experimental measurements in humans provided values such as $95 \mathrm{mN}$ for collision force amplitude [25] and $1-4 \mathrm{kPa}$ for collision pressure [26] in normal phonation. Viscous adhesion stress is of the same order of magnitude as the collision stress (viscous forces in the bridge during separation of nodules): approximately $0.8-1.7 \mathrm{kPa}$ [27]. So, the localized impact zone seems subject to alternating percussion and tearing/shearing forces of the mucus. This is perfectly compatible with the reported early ultramicroscopic lesions after hyperphonation, particularly at the level of the basement membrane of the epithelium [10].

\section{The Driving Force and the Behavioral Component}

In experiments on excised canine hemilarynges, higher subglottal pressure (and closer distance between the arytenoids) appeared positively correlated with peak impact stress during phonation [28]. Measurements in a similar excised canine larynx model showed that increases in subglottal pressure resulted in increased glottal gap and, in turn, increased acceleration and impact stress [29]. Increased subglottal pressure has also been observed as a rule in patients with vocal fold nodules [30].

Patients with vocal fold nodules demonstrated specific psychological traits, such as stress reactivity [31], which could explain how they react to physiological fatigue resulting from (occupational) voice loading. Forcing by enhancing the subglottal pressure can be interpreted in this case as a compensatory behavior.

\section{Conclusions}

Our modelling approach of the hourglass-shaped vibration pattern with limited collision zone reveals interesting insights into the pathogenesis of vocal fold nodules. 
Fig. 6. Male larynx with a 'zip-closure' vibration pattern (moment of maximal closing, dorsal closure defect $2 \mathrm{~mm}$ ). Effect of subglottal pressure on the length of contact zone (from ventral commissure): positive correlation.

Fig. 7. Female larynx (pattern F1) with an hourglass-shaped vibration pattern, as in figure 5. Effect of the degree of dorsal insufficient closure on (1) ventrodorsal length of the contact zone at the moment of maximal closure: negative correlation; (2) lateral amplitude of the ventral chink at the moment of maximal closure: positive correlation; (3) maximal overlap of vocal fold edges at the zone of contact and at the moment of maximal closure: negative correlation. Polynomial fitting curves.

Fig. 8. Female larynx (pattern F1) with an hourglass-shaped vibration pattern, as in figure 5. Effect of the subglottal pressure on (1) ventrodorsal length of the contact zone at the moment of maximal closure: positive correlation; (2) ventrodorsal length of the dorsal chink: negative correlation; (3) lateral amplitude of the ventral chink at the moment of maximal closure: negative correlation; (4) maximal overlap of vocal fold edges at the zone of contact and at the moment of maximal closure: positive correlation.
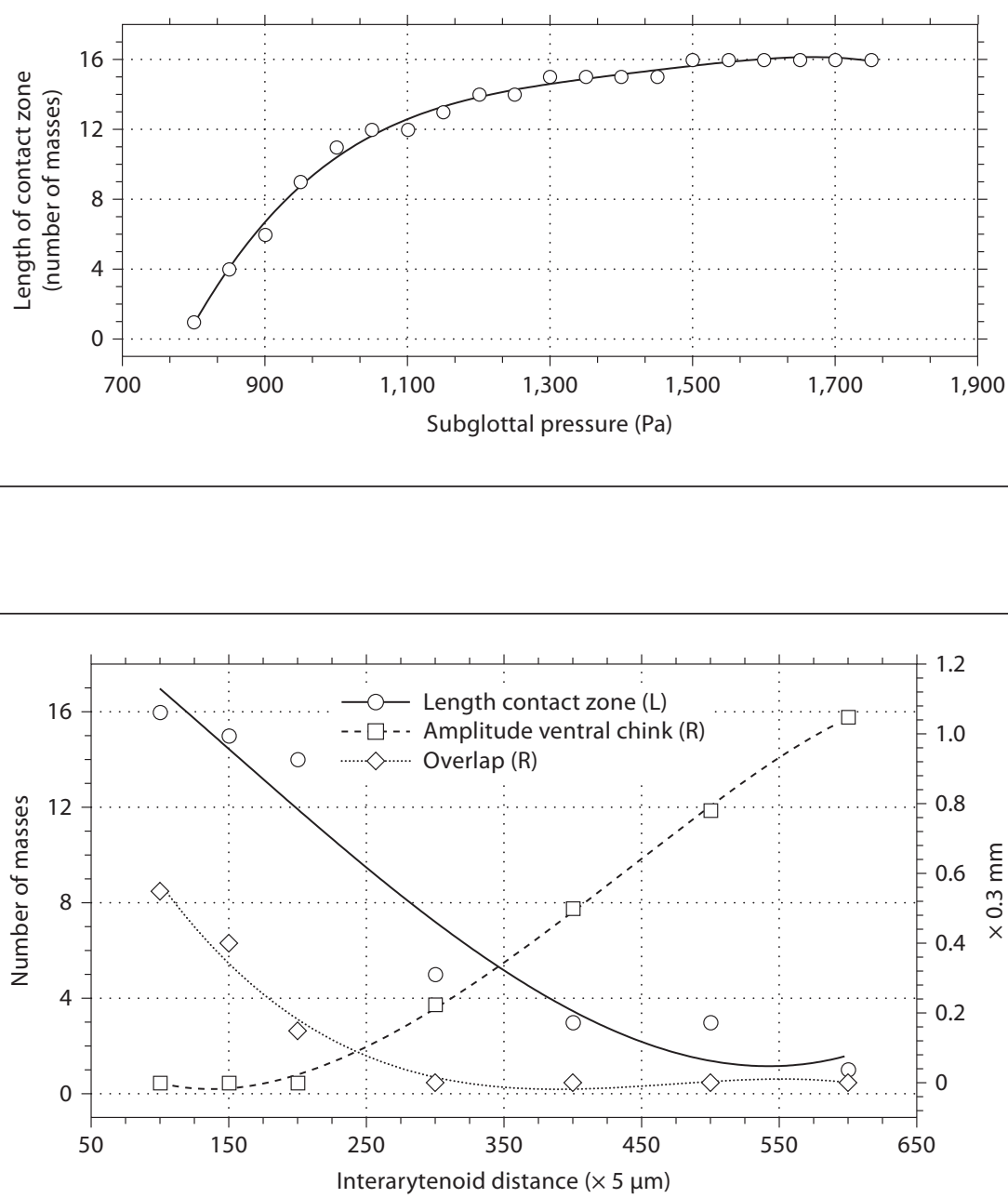
(1) A slightly incomplete dorsal adduction of the vocal fold edges is a first condition for inducing such an hourglass vibration pattern.

(2) Eliciting a limited collision zone, slightly ventral from the middle section of the vibrating vocal fold, is only possible with a small degree of curving of the rest position of the vocal fold edges in their ventral portion. If absent or minimal, the vibration pattern is systematically (in combination with an incomplete dorsal adduction) that of a 'zip closure' without any specific collision point. This slight curving of the most ventral part of the membranous vocal fold, causing the ventral chink, is an anatomical characteristic differentiating the adult female larynx from the male adult larynx and seems to be related to the angle of the thyroid laminae. Muscular fatigue and resulting vocalis hypotonia seem to enhance this curving and facilitate an hourglass-shaped vibration pattern.

(3) If both these conditions are fulfilled, a sufficient vibration amplitude is required in order to achieve a localized impact zone, corresponding to the typical location of vocal fold nodules. A larger degree of incomplete dorsal adduction needs to be compensated - within physiological limits - by a larger vibration amplitude. This localized mechanical stress on the vocal fold margins can logically be associated with the pathogenesis of vocal fold nodules.

(4) This third condition can be achieved by an increased subglottal pressure and/or by a decrease in active stress of the tension forces between the neighbored vocalis masses.

These last aspects incorporate muscular tension imbalance (dyskinesia) and behavioral aspects in the modelling process: a decrease in active stress is a possible effect of fatigue, and an increase in subglottal pressure a result of effort compensation.

Future research should include time-resolved calculations of impact stress along the vocal fold length in an extended version of the program. These calculations could be compared to the results of measurements using optical methods [32], electroglottographic techniques [33] or direct force [29].

\section{Acknowledgment}

The authors wish to thank Prof. Adrian Fourcin (London) for his highly valuable comments on an earlier version of this article.

\section{References}

$>1$ Nagata K, Kurita S, Yasumoto S, Maeda T, Kawasaki H, Hirano M: Vocal fold polyps and nodules. A 10-year review of 1,156 patients. Auris Nasus Larynx 1983;10(suppl): S27-S35.

2 Johns MM: Update on the etiology, diagnosis and treatment of vocal fold nodules, polyps and cysts. Curr Opin Otolaryngol Head Neck Surg 2003;11:456-461.

3 Türck L: Klinik der Krankheiten des Kehlkopfes und der Luftröhre. Wien, Braumüller, 1866.

4 Hirano M, Kurita S, Matsuo K, Nagata K: Laryngeal tissue reaction to stress; in Lawrence V (ed): Transcripts of the 9th Symposium on Care of the Professional Voice. New York, The Voice Foundation, 1980, Part 2, pp 1020.

5 Dejonckere P, Lebacq J, Laloyaux P, Plaghki L: Etiopathogénie des nodules vocaux. Rev Laryngol Otol Rhinol 1994;115:267-276.

6 Hirano M: Clinical Examination of Voice. Wien, Springer, 1981.

7 Stringer SP, Schaefer SD: Disorders of laryngeal function; in Paparella MM et al (eds): Otolaryngology. Philadelphia, Saunders, 1991, pp 2225-2272.
8 Titze IR: Mechanical stress in phonation. J Voice 1994;8:99-105.

9 Titze IR: Principles of Voice Production. Englewood Cliffs, Prentice Hall, 1994.

10 Gray SD, Titze IR, Lusk RP: Electron microscopy of hyperphonated vocal cords. J Voice 1987;1:109-115.

11 Dikkers FG, Nikkels PGJ: Benign lesions of the vocal folds: histopathology and phonotrauma. Ann Otol Rhinol Laryngol 1995; 104:698-703.

12 Dejonckere PH: Gender differences in the prevalence of occupational voice disorders: some anatomical factors possibly contributing; in Dejonckere PH (ed): Occupational Voice, Care and Cure. The Hague, Kugler Publications, 2001, pp 11-20.

13 Kob M: Physical modelling of the singing voice; doctoral dissertation, RWTH Aachen University, Aachen, 2002.

14 Kob M: Singing voice modelling - As we know it today. Acta Acust Acust 2004;90: 649-661.

15 Titze IR, Strong WJ: Normal modes in vocal cord tissues. J Acoust Soc Am 1975;57:736749 .
16 Södersten M, Lindestadt PA: Glottal closure and perceived breathiness during phonation in normally speaking subjects. J Speech Hear Res 1990;33:601-611.

17 Södersten M: Vocal fold closure during phonation; PhD thesis, Huddinge University Hospital, Stockholm, 1994.

18 Biever DM, Bless DM: Vibratory characteristics of the vocal folds in young, adult and geriatric women. J Voice 1989;3:120-131.

19 Sulter AM, Schutte HK, Miller DG: Standardized laryngeal videostroboscopic rating: differences between untrained and trained male and female subjects, and effects of varying sound intensity, fundamental frequency and age. J Voice 1996;10:175-189.

20 Morrison MD, Nichol H, Rammage LA: Diagnostic criteria in functional dysphonia. Laryngoscope 1986;94:1-8.

21 Hirano M, Matsuo K, Kakita Y, Kawasaki H, Kurita S: Vibratory behavior versus the structure of the vocal fold; in Titze IR, Scherer RC (eds): Vocal Fold Physiology. Biomechanics, Acoustics and Phonatory Control. Denver, The Denver Center of the Performing Arts, 1983, pp 26-40. 
22 Hirano M, Kiyokawa K, Kurita S: Laryngeal muscles and glottic shaping; in Fujimura $\mathrm{O}$ (ed): Vocal Physiology: Voice Production, Mechanisms and Functions. New York, Raven Press, 1988, pp 49-65.

23 Fried MP, Meller SM: Adult laryngeal anatomy; in Fried MP (ed): The Larynx, ed 2. St Louis, Mosby, 1995.

24 Stemple JC, Stanley J, Lee L: Objective measures of voice production in normal subjects following prolonged voice use. J Voice 1995; 9:127-133.

25 Gunter HE, Howe RD, Zeitels SM, Kobler JB, Hillman RE: Measurement of vocal fold collision forces during phonation. J Speech Lang Hear Res 2005;48:567-576.
26 Hess MM, Verdolini K, Bierhals W, Mannsmann U, Gross M: Endolaryngeal contact pressures. J Voice 1998;12:50-67.

27 Decker GZ: Modeling the mechanical effects of liquid mediated adhesion between the human vocal folds; thesis, Brigham Young University, 2006.

28 Jiang JJ, Titze IR: Measurement of vocal fold intraglottal pressure and impact stress. J Voice 1994;8:132-144.

29 Jiang JJ, Shah AG, Hess MM, Verdolini K, Banzali FM, Hanson DG: Vocal fold impact stress analysis. J Voice 2001;15:4-14.

30 Kuo J, Holmberg EB, Hillman RE: Discriminating speakers with vocal nodules using aerodynamic and acoustic features. Proc Int Conf Acoust Speech Signal Process, Phoenix, 1999, vol 1, pp 77-80.
31 Roy N, Bless DM, Heisey D: Personality and voice disorders: a multitrait-multidisorder analysis. J Voice 2000;14:521-548.

32 Spencer M, Siegmund T, Mongeau L: Determination of superior surface strains and stresses, and vocal fold contact pressure in a synthetic larynx model using digital image correlation. J Acoust Soc Am 2008;123: 1089-1103.

33 Verdolini K, Hess MM, Titze IR, Bierhals W, Gross M: Investigation of vocal fold impact stress in human subjects. J Voice 1999;13: 184-202. 